18. Юрицына Н.А., Васюков В.М. Чужеродные виды семейства Brassicaceae Burnett в сообществах засоленных экотопов юго-востока Европы // Российский журнал биологических инвазий. 2019. Т. 12, № 2. С. 123-135.

19. Голуб В.Б., Кузьмина Е.Г., Юрицына Н.А. Сообщества с доминированием Tamarix ramosissima в долине Нижней Волги // Український фітоценологічний збірник. 1998. Серия А. Вып. 1 (9). С. 52-60.

20. Голуб В.Б., Юрицына Н.А. Некоторые галофитные сообщества Волго-Уральского Междуречья // Бюл. Самарская Лука. 2001. № 11/01. С. 29-37.
21. Юрицына Н.А. Растительность засоленных местообитаний на юго-восточной границе Европы // Аридные экосистемы. 2012. Т. 18, № 4 (53). С. 55-62. (Yuritsyna N.A. Vegetation of Saline Habitats on Southeastern Border of Europe // Arid Ecosystems. 2012. T. 2, № 4. P. 239-244).

Работа выполнена в рамках госзаданий № AAAA-A17-117112040039-7, № $\quad A A A A-A 17-$ 117112040040-3.

\title{
INVASIONS OF BIDENS FRONDOSA L. (ASTERACEAE) IN COMMUNITIES OF SALINE SOILS OF SOUTH-EAST EUROPE
}

(C) 2019

Yuritsyna Natalia Alekseevna, doctor of biological sciences, senior researcher of Phytodiversity Problems Laboratory

Vasjukov Vladimir Mikhailovich, candidate of biological sciences, researcher of Phytodiversity Problems Laboratory

Saksonov Sergey Vladimirovich, doctor of biological sciences, professor, director Institute of Ecology of the Volga River Basin of the Russian Academy of Sciences - branch of the Samara

Federal Research Center of the Russian Academy of Sciences (Togliatti, Samara Region, Russian Federation)

Abstract. Bidens frondosa is an invasive xenophyte which is naturalized in vegetative communities on the territory of the Southeast of Europe. The natural area of $B$. frondosa is in the North America. The secondary one is on the territory of Eurasia, here $B$. frondosa forces out native $B$. tripartita that is explained by competitive superiority of the North American species on growth rates and seed efficiency on soils of different fertility and water regime. In the secondary area in Eurasia B. frondosa grows on banks of reservoirs and water currents as well as on other damp habitats (including disturbed ones) often in large quantities. This species is also found on saline soils of the European Southeast. It is registered in communities of association Atriplici aucheri-Tamaricetum ramosissimae Golub et al. 1998 belonging to class NerioTamaricetea Br.-Bl. et Bolòs 1958 order Tamaricetalia ramosissimae Golub in Barmin 2001 alliance Elytrigio repentisTamaricion ramosissimae Golub in Barmin 2001, in one of its subassociations - A.au.-T.r. althaeetosum Golub et al. 1998 , but there $B$. frondosa is the diagnostic taxon as well as the constant species that is met in all of its described coenosis.

Keywords: saline ecotops; vegetative communities; alien species; agriophyte; xenophyte; Southeast of Europe; Volga delta; Volga-Akhtuba flood-plain; Western Substeppe Ilmens; Bidens frondosa; Asteraceae; subassociation Atriplici aucheri-Tamaricetum ramosissimae althaeetosum Golub et al. 1998.

$* * *$

\section{СРАВНИТЕЛЬНАЯ ХАРАКТЕРИСТИКА ФАКТОРОВ ОРГАНИЗАЦИИ СЕГЕТАЛЬНЫХ СООБЩЕСТВ ЛЕНИНГРАДСКОЙ ОБЛАСТИ И РЕСПУБЛИКИ БАШКОРТОСТАН}

(C) 2019

Ямалов Сергей Маратович, доктор биологических наук,

ведущий научный сотрудник лаборатории дикорастущей флоры и интродукции травянистых растений

Лебедева Мария Владимировна, кандидат биологических наук,

старший научный сотрудник группы тропических и субтропических растений

Южно-Уральский ботанический сад-институт Уфимского федерального исследовательского изентра РАН (2. Уфа, Российская Федерачия)

Лунева Наталья Николаевна, кандидат биологических наук, заведующий сектором гербологии лаборатории фитосанитарной диагностики и прогнозов

Всероссийский научно-исследовательский институт защзиты растений

(2. Санкт-Петербург, Российская Федерачия)

Хасанова Гульназ Римовна, кандидат биологических наук,

доцент кафедры почвоведения, ботаники и селекции растений

Башкирский государственный аграрный университет (г. Уфа, Российская Федерация)

Шигапов Зиннур Хайдарович, доктор биологических наук, директор

Южно-Уральский ботанический сад-институт Уфимского федерального исследовательского иентра РАН (2. Уфа, Российская Федеращия)

Аннотация. В работе приведены результаты непрямого ординационного анализа сегетальных (сорнополевых) сообществ двух контрастных по эдафо-климатическим условиям регионов - Ленинградской обла- 

сообществ, выполненных авторами в период 2000-2018 гг. в посевах зерновых и пропашных культур. Для получения данных по экологическим характеристикам местообитаний проведен подсчет экологических статусов сообществ по 9 шкалам Д.Н. Цыганова. Для анализа привлечены значения шкал, соответствующих климатическим факторам (термоклиматическая шкала, шкала суровости зимнего периода, шкала аридностигумидности климата), эдафическим факторам (солевой режим, кислотность почв, богатство азотом, переменность увлажнения), а также шкалы увлажнения почв и освещенности-затенения. Определены диапазоны, занимаемые сообществами по каждой из шкал. Для выявления экологических закономерностей распределения видов и сообществ и определения ведущих факторов использован метод непрямой DCA-ординации с применением пакета программ CANOCO 4.5. Показано, что сегетальная растительность сравниваемых регионов существенно различается по набору шкал, отражающих ведущие эдафо-климатические факторы организации. Только термоклиматическая шкала и шкала переменности увлажнения являются общими для двух регионов. В дифференциации флористического состава сегетальных сообществ в Ленинградской области наибольшую роль играют шкалы, отражающие богатство почв азотом, переменности увлажнения и суровости зимнего периода. В Республике Башкортостан в дифференциации участвуют шкалы аридностигумидности, солевого режима, освещенности/затенения, увлажнения и кислотности почв. Большее число шкал определяется большим разнообразием зональных типов растительности на территории РБ, которые связаны с ландшафтами лесной, лесостепной и степной зон, а также горно-лесного пояса Южного Урала, в сравнении с Ленинградской областью, где зональная растительность относится только к подзонам южной и средней тайги. Исключение составляет шкала освещенность/затенение, высокие значения корреляции с которой связаны со значительной долей подсолнечника и кукурузы в спектре выращиваемых культур в Республике Башкортостан.

Ключевые слова: сорные виды; сорно-полевая растительность; сегетальные сообщества; флористический состав; ординационный анализ; DCA-ординация; климатические факторы; эдафические факторы; экологические шкалы; Республика Башкортостан; Южный Урал; Ленинградская область.

Данные по флористическому составу сорно-полевых (сегетальных) сообществ и эколого-биологические особенности видов сорных растений являются обязательной составляющей научно-обоснованной системы контроля сорного компонента агрофитоценозов. Флористический состав сегетальных сообществ зависит от ряда факторов, которые можно условно объединить в две группы: 1) группа агроценотических факторов: система севооборотов, набор культур, уровень агротехники и др. [1-3] и 2) группа эдафо-климатических факторов: условия климата, увлажнение местообитаний, типы почв и др. [4-9]. Вторая группа факторов изменяется существенно в разных регионах и, несмотря на азональный характер сегетальных сообществ, достаточно существенно влияет на видовой состав, который представлен как видами с широкой экологией и космополитным ареалом, так и апофитами с узким ареалом из состава местной флоры [10].

В данной работе авторами поставлена задача сравнить ведущие факторы организации сегетальных сообществ двух контрастных по эдафо-климатическим условиям регионов - Ленинградской области (ЛО) и Республики Башкортостан (РБ), по которым на настоящий момент накоплен достаточный фактический материал.

Природные условия районов исследования

Площадь территории исследования в пределах РБ составляет больше 100 тыс. км². Протяженность с севера на юг составляет около 550 км, с запада на восток - около 450 км. По строению поверхности тер- ритория включает восточную окраину Русской равнины (Башкирское Предуралье), значительный участок горной полосы Южного Урала и часть Зауральского пенеплена (Башкирское Зауралье) [11]. Основной геоморфологический фон рельефа определяется 2 типами мегарельефа: равнинным и горным [12]. На территории исследования выделяются четыре геоботанические зоны растительности: бореально-лесная, широколиственно-лесная, лесостепная и степная. Для Республики Башкортостан в целом характерен континентальный климат (табл. 1).

Площадь территории исследования в пределах ЛО составляет более 84 тыс. км². Наибольшая протяженность с севера на юг составляет около 320 км, с запада на восток - около 500 км. Высота над уровнем моря не превышает 100 м. Большая часть территории области находится в пределах северо-западной окраины Русской плиты и представляет собой пологохолмистую равнину, ступенями повышающуюся в южном направлении. Центральную часть занимает Ижорская возвышенность, сложенная карбонатными породами. Восток области занимает северную оконечность Валдайско-Онежской возвышенности, в которую входят Тихвинская гряда и Вепсовская возвышенность. Вся территория области располагается в пределах средней и южной тайги [13]. Ленинградская область (табл. 1) имеет два типа климатических условий: на большей части теплый влажный континентальный климат, а на северо-востоке - субарктический $[14 ; 15]$.

таблица 1 - Основные климатические показатели района исследования

\begin{tabular}{|l|c|c|c|c|c|}
\hline \multirow{2}{*}{\multicolumn{1}{|c|}{ Показатель }} & \multicolumn{2}{|c|}{ Республика Башкортостан } & \multicolumn{2}{|}{ Ленинградская область } \\
\cline { 2 - 6 } & Предуралье & $\begin{array}{c}\text { Горно-лесной } \\
\text { пояс Южного } \\
\text { Урала }\end{array}$ & $\begin{array}{c}\text { Централь- } \\
\text { Заяралье часть и } \\
\text { юго-запад }\end{array}$ & $\begin{array}{c}\text { Северо- } \\
\text { восток }\end{array}$ \\
\hline Среднегодовая температура, ${ }^{\circ} \mathrm{C}$ & $+2,0 \ldots+2,4$ & $+0,6 \ldots+1,6$ & $+0,9 \ldots+1,9$ & $+3,9 \ldots+4,7$ & $+2,8 \ldots+3,5$ \\
\hline Сумма температур выше $+10^{\circ} \mathrm{C}$ & $1800-2350$ & $1200-2000$ & $1700-2300$ & $1700-1900$ & $1400-1500$ \\
\hline $\begin{array}{l}\text { Продолжительность безморозного пери- } \\
\text { ода, дни }\end{array}$ & $90-130$ & $40-120$ & $100-130$ & $120-130$ & $105-112$ \\
\hline Среднегодовое количество осадков, мм & $650-400$ & $750-450$ & $580-390$ & $633-689$ & $654-726$ \\
\hline
\end{tabular}




\section{Методика}

В основу работы положено 1726 геоботанических описаний сегетальных сообществ, из которых 835 описаний представляют ЛО, 891 описание выполнены на территории РБ. Описания выполнены авторами в период 2000-2018 гг. в посевах зерновых и пропашных культур по стандартным методикам.

Для получения данных по экологическим характеристикам местообитаний проведен подсчет экологических статусов сообществ по 9 шкалам Д.Н. Цыганова [16]. Для анализа привлечены значения шкал, соответствующих климатическим факторам (термоклиматическая шкала, шкала суровости зимнего периода, шкала аридности-гумидности климата), эдафическим факторам (солевой режим, кислотность почв, богатство азотом, переменность увлажнения), а также шкалы увлажнения почв и освещенностизатенения. Определены диапазоны, занимаемые сообществами по каждой из шкал. Для выявления экологических закономерностей распределения видов и сообществ и определения ведущих факторов использован метод непрямой DCA-ординации с применением пакета программ CANOCO 4.5 [17] и JUICE [18].

\section{Результаты}

Результаты DCA-ординации показаны на рис. 1. В таблице 2 приведены значения коэффициента корреляции расчетных значений эколого-ценотического статуса сообществ с 2 осями DCA-ординации. Видно, что первые оси ординации имеют максимальные значения нагрузки как в РБ, так и в ЛО $(0,44$ и 0,3 соответственно). Поэтому шкалы, для которых отмечены высокие показатели корреляционной связи с первой осью, рассматриваются нами как ведущие факторы, детерминирующие распределение сообществ в ординационном пространстве.

Анализ значений коэффициента корреляции разных шкал по первой оси показал следующие закономерности. Для сегетальных сообществ ЛО наблюдается наиболее высокая корреляция с первой осью ординации 4 шкал $(\mathrm{r}>0,4)$ : богатства азотом, переменности увлажнения, термоклиматического фактора и суровости зимнего периода. По второй оси высокое значение коэффициента корреляции имеет только шкала кислотности почв.

В РБ картина несколько иная. Шкал, имеющих значение $r=0,4-0,5$ по первой оси несколько больше, чем в ЛО. В эту группу вошли термоклиматиче- ская шкала, аридность-гумидность климата, переменность увлажнения, солевой режим, освещенность/затенение, увлажнение и кислотность почв. Причем первые три шкалы связаны и с первой и со второй осью ординации. Только со второй осью в РБ связан также одна шкала - суровость зимнего периода. Перечисленные шкалы, имеющие максимальные показатели по первой оси (4 фактора в ЛО, и 7 в РБ), отражают ведущие экологические факторы в рассматриваемых регионах.

В группу общих шкал для ЛО и РБ, имеющих высокие значения корреляции, входят только две: термоклиматическая и переменность увлажнения. По второй оси в ЛО значение $(r>0,4)$ имеет шкала кислотности почв, в РБ высокие значение только по второй оси получила шкала суровость зимнего периода $(r>0,65)$.

Результаты непрямой ординации сообществ хорошо дополняет ординация видов сегетальных сообществ (рис. 2). На рисунке показаны виды, встречающиеся в сообществах с высоким постоянством (они заняли центральное положение в пространстве осей), и виды, формирующие границы ординационного облака.

Среди ведущих факторов в РБ наиболее наглядна дифференциация видов вдоль первой оси по шкалам аридности-гумидности климата и солевого режима, а также по криоклиматической шкале вдоль второй оси.

Правую верхнюю часть облака занимают виды с широким диапазоном (более 10 ступеней) по шкале аридности-гумидности, который охватывает, в том числе, экстрааридную ступень, это такие виды, как Panicum milleaceum, Lactuca tatarica и др. В левой нижней части облака расположены виды с более узким диапазоном (Viola arvensis, Galeopsis bifida), нижняя граница которого соответствует мезоаридным и субаридным ступеням шкалы.

По шкале солевого режима в правую часть облака попали виды, экологический диапазон которых начинается с довольно богатых почв - Amaranthus retroflexus, Atriplex prostrata, Avena fatua, Camelina microcarpa, Echinochloa crusgalli, Lactuca serriola, Lactuca tatarica и др. Крайне правое положение на оси занимают виды - Atriplex sagittata и A. prostrata, верхняя граница диапазона которых достигает ступень сильнозасоленных почв.

Таблица 2 - Значения коэффициента корреляции (r) расчетных значений эколого-ценотического статуса сообществ ЛО и РБ с осями DСА-ординации

\begin{tabular}{|l|c|c||c|c|}
\hline \multirow{2}{*}{\multicolumn{1}{|c|}{ Шкала }} & \multicolumn{2}{c||}{ Ленинградская область } & \multicolumn{2}{c|}{ Республика Башкортостан } \\
\cline { 2 - 5 } & 1 ось & 2 ось & 1 ось & 2 ось \\
\hline Термоклиматический (TM) & $-\mathbf{0 , 5 6}$ & $-0,14$ & $\mathbf{0 , 4 8}$ & $\mathbf{0 , 5 3}$ \\
\hline Аридность-гумидность (OM) & 0,07 & 0,24 & $-\mathbf{0 , 4 6}$ & $-\mathbf{0 , 4 9}$ \\
\hline Суровость зимнего периода (CR) & $-\mathbf{0 , 4 1}$ & $-0,11$ & 0,14 & $\mathbf{0 , 6 5}$ \\
\hline Увлажнение почв (HD) & 0,06 & 0,29 & $-\mathbf{0 , 4 1}$ & $-0,21$ \\
\hline Солевой режим (TR) & $-0,37$ & $-0,10$ & $\mathbf{0 , 4 6}$ & 0,27 \\
\hline Кислотность почв (RC) & $-0,09$ & $-\mathbf{0 , 4 6}$ & $\mathbf{0 , 4 0}$ & 0,16 \\
\hline Богатство азотом (NT) & $\mathbf{- 0 , 5 2}$ & $-0,11$ & 0,33 & 0,08 \\
\hline Переменность увлажнения (FH) & $-\mathbf{0 , 5 5}$ & $-0,12$ & $\mathbf{0 , 4 1}$ & $\mathbf{0 , 4 0}$ \\
\hline Освещенность/затенение (LC) & 0,07 & 0,19 & $-\mathbf{0 , 4 1}$ & 0,02 \\
\hline Нагрузка на ось (еіgеnvalues) & $\mathbf{0 , 4 4}$ & 0,34 & 0,3 & 0,23 \\
\hline
\end{tabular}

Примечание. Жирным выделены значения факторов выше 0,4. 

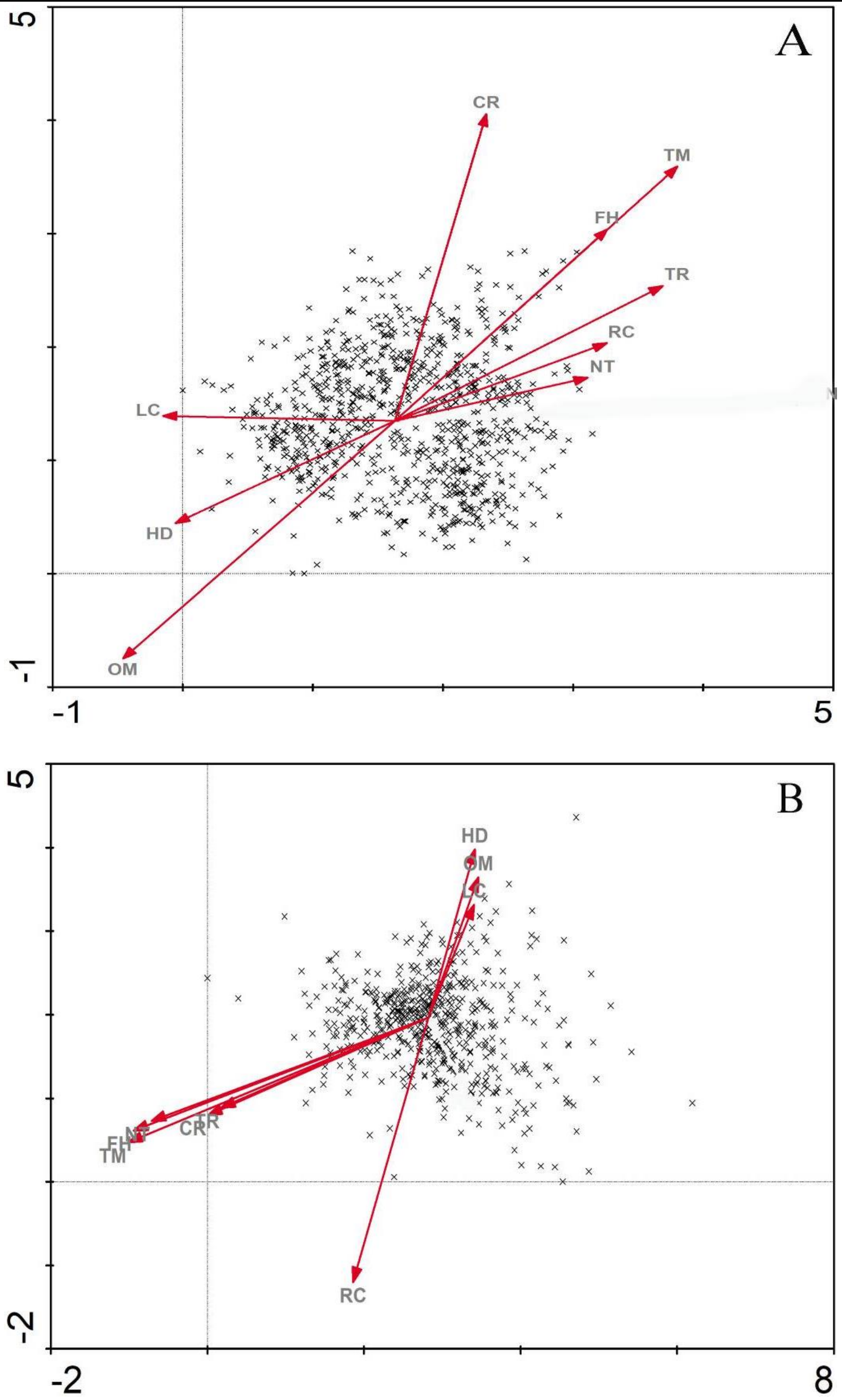

Рисунок 1 - DCA-ординация сегетальных сообществ

Республики Башкортостан $(A)$ и Ленинградской области (B) 
Ямалов С.М., Лебедева М.В., Лунева Н.Н., Хасанова Г.Р., Шигапов 3.Х.

По криоклиматической шкале (суровости зимнего периода) виды с широким диапазоном (более 10 ступеней), такие как Galeopsis bifida, Avena fatua, Camelina microcarpa, Sonchus asper, Sonchus oleraceus, Carum carvi локализованы в нижней части ординационного облака. Виды, приуроченные к ступени от умеренных и до очень теплых зим: Convolvulus arvensis, Lactuca tatarica, Amaranthus retroflexus, Lactuca serriola, Linaria vulgaris, Echinochloa crusgalli, заняли верхнюю часть облака.

В ЛО наиболее наглядна дифференциация видов вдоль первой оси по шкале термоклиматического фактора и суровости зимнего периода, а также кислотности почвы - вдоль второй.

По термоклиматической шкале и по шкале суровости зимнего периода в ЛО виды с широким диапазоном (12 ступеней), охватывающим ступени от субарктической до средиземноморской (Elytrigia repens, Capsella bursa-pastoris, Stellaria media) сменяются более теплолюбивыми видами (Sonchus oleraceus, Solanum nigrum) с более узким диапазоном (8-9 ступеней), нижняя граница которого начинается от субтропической ступени (Amaranthus blitoides).
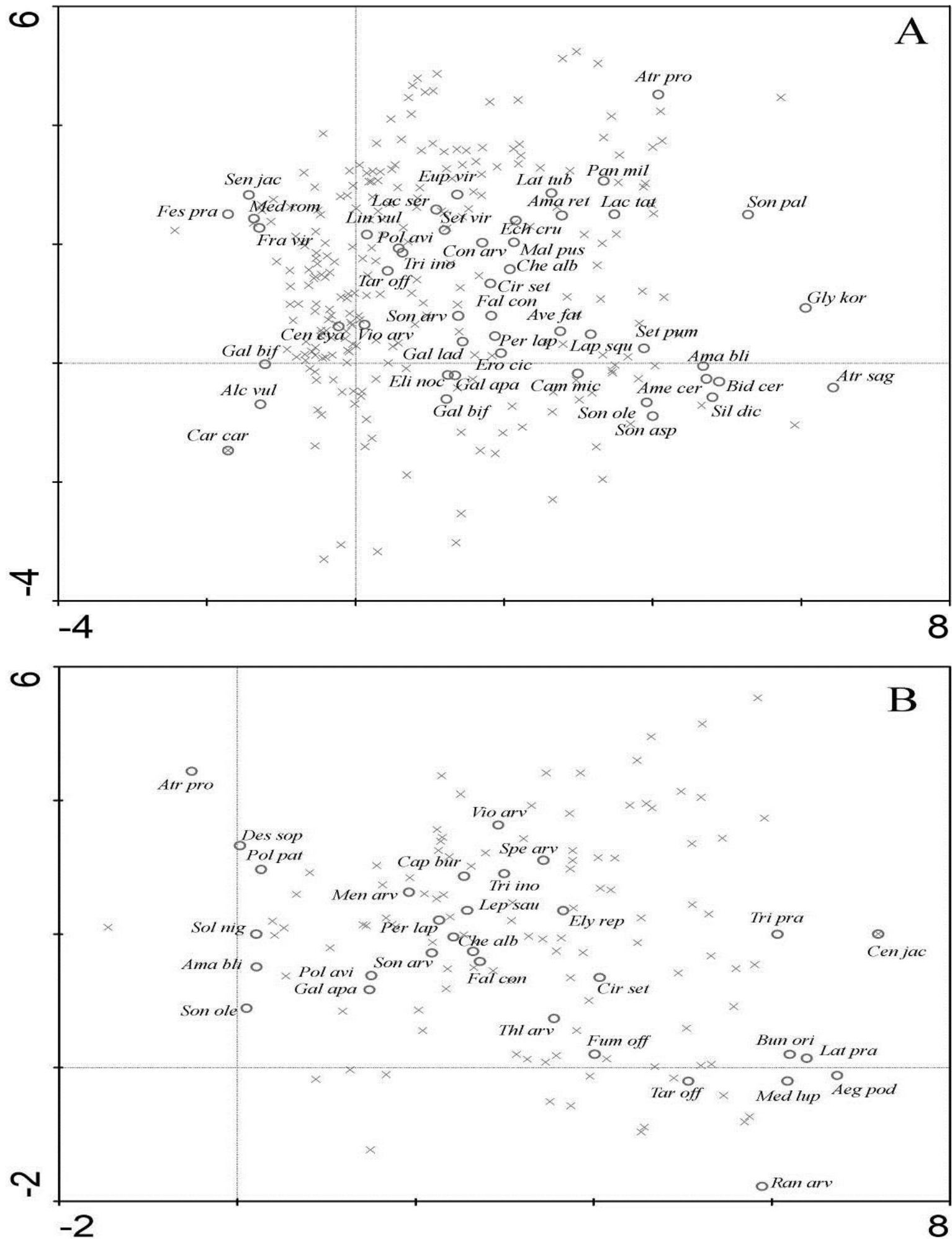

Рисунок 2 - DCA-ординация видов сегетальных сообществ Республики Башкортостан $(A)$ и Ленинградской области $(B)$ 
Ямалов С.М., Лебедева М.В., Лунева Н.Н., Хасанова Г.Р., Шигапов 3.Х.

По шкале кислотности почвы виды с широким диапазоном (10 ступеней) от очень кислых до слабощелочных почв (Capsella bursa-pastoris, Descurainia Sophia, Mentha arvensis, Persicaria lapathifolia) локализованы в верхней части ординационного облака. Виды с узким диапазоном (4-5 ступеней) от слабокислых до слабощелочных почв (Aegopodium podagraria, Sonchus oleraceus, Ranunculus arvensis, Bunias orientalis, Medicago lupulina) - в нижней части.

\section{Заключение}

Выполненный ординационный анализ и оценка эколого-ценотического статуса сообществ показали, что сегетальная растительность РБ и ЛО существенно различаются по набору шкал, отражающих ведущие эдафо-климатические факторы организации. Из 9 шкал, взятых в анализ, только 2 шкалы являются общими для двух регионов. Это термоклиматическая шкала и шкала переменности увлажнения. Первая отражает влияние географического расположения, вторая в большей степени - локальный экологический режим местообитания. В дифференциации флористического состава сегетальных сообществ в ЛО наибольшую роль играют шкалы, отражающие богатство почв азотом, переменности увлажнения и суровости зимнего периода. В РБ в дифференциации участвуют больше шкал: аридность-гумидность, солевой режим, освещенность/затенение, увлажнение и кислотность почв. Это объясняется большим разнообразием зональных типов растительности на территории РБ, которые связаны с ландшафтами лесной, лесостепной и степной зон, а также горно-лесного пояса Южного Урала, в сравнении с ЛО, где зональная растительность относится только к подзонам южной и средней тайги. Исключение составляет шкала освещенность/затенение, высокие значения корреляции с которой связаны со значительной долей подсолнечника и кукурузы в спектре выращиваемых культур в РБ.

Существенно различаются и группы видов, индицирующие различия в наборе ведущих шкал. Так, в РБ в эту группу входят такие виды, как Amaranthus retroflexus, Atriplex prostrata, A. sagittata, Avena fatua, Camelina microcarpa, Carum carvi, Convolvulus arvensis, Echinochloa crusgalli, Galeopsis bifida, Lactuca serriola, L. tatarica, Linaria vulgaris, Panicum milleaceum, Sonchus asper, Sonchus oleraceus, Viola arvensis. В ЛО в эту группу входят такие виды, как Aegopodium podagraria, Amaranthus blitoides, Bunias orientalis, Capsella bursa-pastoris, Descurainia sophia, Elytrigia repens, Medicago lupulina, Mentha arvensis, Persicaria lapathifolia, Ranunculus arvensis, Solanum nigrum, Sonchus oleraceus, Stellaria media.

\section{Список литературы:}

1. Багрикова Н.А. Сорно-полевая растительность Крыма: автореф. дис. ... д-ра биол. наук. Ялта, 2012. $40 \mathrm{c}$.

2. De Mol F., Redwitz C., Gerowitt B. Weed species composition of maize fields in Germany is influenced by site and crop sequence // Weed Research. 2015. 55 (6). P. 574-585.

3. Хасанова Г.Р., Лебедева М.В., Миркин Б.М., Наумова Л.Г. Последствия изменения сельскохозяй- ственных технологий для распределения сегетальных растительных сообществ и видов в Республике Башкортостан // Экология. 2017. № 5. С. 396-399.

4. Mirkin B.M., Slepcova N.P., Kononov K.E. Segetal Vegetation of Central Yakutia // Folia geobotanica et phytotaxonomica. 1988. Vol. 23. № 1. P. 113-143.

5. Matzdof B., Zerbe S. Segetalvegetation der Uckermark (NO-Branderburg) unter dem Einfluss von biologisch-dynamischer und konventioneller Bewirtschaftung // Verh. Bot. Ver. Berlin Brandenburg. Berlin. 2000. P. 87-118.

6. Lososová Z., Chytrý M., Cimalová S., Kropáč Z., Otýpková Z., Pyšek P., Tichý L. Weed vegetation of arable land in Central Europe: Gradients of diversity and species composition // Journal of Vegetation Science. 2004. № 15. P. 415-422. DOI: 10.1111/j.1654-103.2004.tb02279.x.

7. Хасанова Г.Р., Ямалов С.М. Разнообразие сегетальной растительности Южного Урала: вклад зонально-климатического фактора // Известия Самарского научного центра РАН. 2013. Т. 15, № 3-5. C. $1490-1494$.

8. Šilc U., Lososová Z., Vrbničanin S. Weeds shift from generalist to specialist: narrowing of ecological niches along a north-south gradient // Preslia. 2014. Vol. 86. P. 35-46.

9. Nowak A., Nowak S. Nobis M., Nobis A. Crop type and altitude are the main drivers of species composition of arable weed vegetation in Tajikistan // Weed research. 2015. P. 1-12. DOI: 10.1111/wre.12165.

10. Хасанова Г.Р., Голованов Я.М., Ямалов С.М. Динамика таксономического спектра сегетальной флоры Южного Урала // Известия Оренбургского государственного аграрного университета. 2016. № 1 (57). C. $133-135$.

11. Определитель высших растений Башкирской АССР / Ю.Е. Алексеев, Е.Б. Алексеев, К.К. Габбасов и др. М.: Наука, 1988. 316 с.

12. Башкортостан: Краткая энциклопедия. Уфа: Научное изд-во Башкирская энциклопедия, 1996. 672 с.

13. Иллюстрированный определитель растений Ленинградской области / под ред. А.Л. Буданцева и Г.П. Яковлева. М.: Товарищество научных изданий КМК, 2006. 799 с.

14. Исаченко А.Г., Дашкевич 3.В., Карнаухова Е.Н. Физико-географическое районирование Северо-Запада РСФСР. Л.: Изд-во Ленинградского университета, 1965. 248 c.

15. Ленинградская область: климат. 2008-2012 [Электронный pecypc] // http://x47.ru/1.php.

16. Цыганов Д.Н. Фитоиндикация экологических режимов в подзоне хвойно-широколиственных лесов. М.: Наука, 1983. 197 с.

17. Ter Braak C.J.F., Šmilauer P. CANOCO Reference Manual and CanoDraw for Windows User's Guide: Software for Canonical Community Ordination (version 4.5). New York: Microcomputer Power. 2002. 500 p.

18. Tichy L. JUICE, software for vegetation classification // Journal vegetation science. 2002. № 13. P. 451453. DOI: $10.1111 / \mathrm{j} .1654-1103.2002 . t b 02069 . x$.

Статья публикуется при поддержке РФФИ (проекты № 17-44-020402 p_a, № 19-016-00135) и средств государственного бюджета (№ A18-118011990151-7). 


\section{COMPARISON OF WEED COMMUNITIES ORGANIZATION FACTORS IN THE LENINGRAD REGION AND THE REPUBLIC OF BASHKORTOSTAN}

(C) 2019

Yamalov Sergey Maratovich, doctor of biological sciences,

leading researcher of Wild-Growing Flora and Herbasceous Plants Introduction Laboratory

Lebedeva Maria Vladimirovna, candidate of biological sciences, senior researcher of Tropical and Subtropical Plants Group

South-Ural Botanical Garden-Institute of the Ufa Federal Research Centre of Russian Academy of Sciences (Ufa, Russian Federation)

Luneva Natalya Nikolaevna, candidate of biological sciences, head of Herbology Sector of Phytosanitary Diagnostics and Forecasts Laboratory All-Russian Institute of Plant Protection (Saint Petersburg, Russian Federation)

Khasanova Gulnaz Rimovna, candidate of biological sciences, associate professor of Soil Science, Botany and Selection Department

Bashkir State Agrarian University (Ufa, Russian Federation)

Shigapov Zinnur Khaidarovich, doctor of biological sciences, director

South-Ural Botanical Garden-Institute of the Ufa Federal Research Centre of Russian Academy of Sciences (Ufa, Russian Federation)

Abstract. This paper considers the results of the ordination analysis of weed communities in two regions - the Leningrad Region (LR) and the Republic of Bashkortostan (RB). The dataset includes 1726 relevés of the weed communities executed by the authors during 2000-2018 in cereal and root crops. The calculation of the ecological statuses of communities on 9 scales of D.N. Tsyganov is carried out for ecological characteristics of habitats. The values of the scales corresponding to climatic factors (thermoclimatic scale, cryoclimatic scale, aridity-gumidity scale), edafic factors (salt regime, soil acidity, nitrogen richness, variability of moistening) as well as scales of soil moisture and lightning are attracted to the analysis. The communities ranges on each scale are determined. The detrended correspondent analysis (DCA-ordination) with CANOCO 4.5 software package is used for the identification of ecological patterns of species and communities distribution and definition of the main drivers. It is demonstrated that the sets of the scales reflecting main ecological drivers significantly differ for the compared regions. Only the thermoclimatic scale and the scale of variability of moistening are common for both regions. The scales of nitrogen richness, variability of moistening and cryoclimatic influence generally on floristic composition differentiation in the LR. The scales of aridity-gumidity, the salt regime, lightning, moistening and soil acidity determine the floristic differentiation in the RB. A large number of scales in RB are defined by a variety of zonal vegetation types in the region which are connected with landscapes of forest, forest-steppe and steppe zones as well as a mountain-forest belt of the Southern Ural. The zonal vegetation of LR belongs only to subzones of the southern and average Taiga. The exception is the lightning scale which high values of correlation are connected with a considerable share of sunflower and corn in cultivated crops in RB.

Keywords: weed species; weed vegetation; floristic composition; ordination analysis; detrended corresponded analysis; climatic factors; edafic factors; environmental drivers; ecological scales; Republic of Bashkortostan; Southern Ural; Leningrad Region. 